\title{
ESTUDO ANALÍTICO DO PROCESSO LICITATÓRIO AMBIENTAL PARA EMPREENDIMENTOS EÓLICOS NO ESTADO DO RIO GRANDE DO NORTE
}

\author{
M.H.M. Bezerra'; C.S.M. Melo'; M.M.A. Nunes' e T.P.N. Mesquita² \\ ${ }^{1}$ Universidade Federal do Rio Grande do Norte (UFRN) \\ ${ }^{2}$ Universidade Potiguar (UNP) \\ marcelohugu@hotmail.com
}

Artigo submetido em fevereiro/2013 e aceito em maio/2013

\section{RESUMO}

O presente trabalho teve como objetivo analisar o processo licitatório para parques eólicos no estado do Rio Grande do Norte. Para tal finalidade, foram utilizados três critérios: tempo de tramitação, custos monetários e complexidade. Para a coleta de dados foi aplicado um questionário fechado com o gestor de uma empresa de consultoria ambiental e realizada uma entrevista semiestruturada com o subcoordenador de licenciamento de parques eólicos do IDEMA. Além disso, o sítio eletrônico do IDEMA também foi fonte de informação para chegar aos resultados finais da pesquisa. Como resultado, pôde-se constatar que o processo licitatório tem como a etapa mais complexa, devido ao estudo ambiental requisitado, a Licença de Instalação. Conclui-se que o estudo ambiental é fator de maior influência no processo licitatório nos três aspectos estudados e que a Licença Prévia é fator decisivo para a continuidade ou não do processo de licença. Outro ponto conclusivo é a falta de padronização do processo nacional de licenciamento ambiental, sendo fonte de uma série de entraves enfrentados pelo empreendedor.

PALAVRAS-CHAVE: Processo Licitatório, Energia Eólica, Complexidade.

\section{ANALYTICAL STUDY OF THE BIDDING PROCESS FOR WIND FARMS IN THE STATE OF RIO GRANDE DO NORTE}

\begin{abstract}
The present paper aims to analyze Rio Grande do Norte's wind farms' bidding process. To achieve that, the criteria covered: processing time, monetary costs and complexity. A survey was made, in order to collect data from a close environmental consultant. Semi structured interviews with IDEMA's wind farms licensing sub coordinator were also arranged. By the way, IDEMA's website was also information source to the paper's target was met. As a result, it is possible to state
\end{abstract}

that the bidding process's most complex stage is the installation license. It could be concluded that environmental studies are the biggest impact factor in the bidding process, as well as the fact that The Preliminary License can be decisive for the continuity of the licensing process. Finally, it was seen that the lack of national process standards is the source of a series of barriers faced by the entrepreneur.

KEY-WORDS: Bidding Process, Wind Energy, Complexity. 


\section{ESTUDO ANALÍTICO DO PROCESSO LICITATÓRIO AMBIENTAL PARA EMPREENDIMENTOS EÓLICOS NO ESTADO DO RIO GRANDE DO NORTE}

\section{INTRODUÇÃO}

Atualmente, as questões referentes à sustentabilidade estão na pauta dos principais temas e discussões globais, sejam eles políticos, econômicos ou sociais. As organizações são cada vez mais pressionadas a adotarem o conceito de desenvolvimento sustentável como base do seu planejamento organizacional e de suas políticas operacionais, sendo esse um fator indispensável à adequação das tendências atuais de mercado.

Andrade et al. (2002) mostram diversos benefícios da adoção de práticas sustentáveis pelas organizações, tanto do ponto de visto global - como o auxílio à sobrevivência humana quanto do ponto de vista organizacional, como o aproveitamento de oportunidades de mercado e a redução de custos.

Dentre os mercados que desempenham um papel importante para o desenvolvimento sustentável, o setor de energias renováveis vem ganhando cada vez mais notoriedade e espaço. Tal fato é comprovado pelo grande aumento dos investimentos em projetos referentes a esse tipo de energia, além de que nos últimos anos a taxa de investimento de capital em cleantech tecnologia limpa - vem crescendo mais de $50 \%$ ao ano, ritmo superior a qualquer outra categoria (SENGE et al., 2009; SAVITZ, 2007).

A região nordeste brasileira devido à alta incidência de ventos fortes e constantes, além do crescente esforço dos governos para atração de investimentos no setor, tornou-se uma das principais regiões concentradoras de projetos de energia eólica no mundo.

O estado do Rio Grande do Norte merece destaque nesse cenário ao se tornar líder em novos projetos eólicos no Brasil nos últimos seis anos, com previsão de mais de $3.300 \mathrm{MW}$ a serem instalados até 2016, passando de um status de importador de energia para o de provedor energético regional (CERNE, 2012).

Apesar dos investimentos crescentes, um fator de grande limitação para o desenvolvimento de novos parques eólicos no país é em relação à falta de uniformização do processo de licenciamento ambiental, onde cada estado da federação apresenta diferentes exigências aos investidores.

Partindo do exposto anteriormente, este trabalho tem como objetivo avaliar a complexidade do processo para a obtenção do completo licenciamento de um parque eólico no Estado do Rio Grande do Norte, tendo como objetivos específicos identificar o tempo de tramitação das licenças ambientais relativas a empreendimentos eólicos junto ao órgão estadual de meio ambiente do RN, o IDEMA, estimar os custos monetários para a elaboração dessas licenças ambientais e analisar a complexidade de elaboração das referidas licenças.

A presente pesquisa mostra-se relevante ao elucidar e tornar mais transparente esse processo de vital importância para a consolidação da energia eólica como fonte valiosa na matriz energética brasileira, servindo como base para futuros estudos e sugestões de melhorias visando o desenvolvimento sustentável para todos os envolvidos nesse processo. 


\section{PROCEDIMENTOS METODOLÓGICOS}

O presente trabalho caracteriza-se como uma pesquisa qualitativa, visto que os dados foram obtidos através do contato direto e interativo dos pesquisadores com a situação objeto de estudo, sendo a interpretação do fenômeno estudado resultante das perspectivas dos participantes em relação à situação observada (NEVES, 1996).

Silva et al. (2005) afirmam que o trabalho qualitativo exige um roteiro que seja direcionador da pesquisa, mas sem a necessidade de possuir uma estrutura rígida. Os autores afirmam que o primeiro passo da análise consiste em obter os dados que poderão ser coletados por meio de entrevistas semiestruturadas ou através da utilização de questionários, por exemplo. Da posse dos dados, o pesquisador analisa e interpreta as informações colhidas para, posteriormente, fazer a conclusão acerca do fenômeno estudado.

A partir disso, essa pesquisa compõe três fases (BARDIN, 1994):

A pré-análise, que se constitui na elaboração de um plano de trabalho contendo os procedimentos a serem executados no decorrer da pesquisa. Nessa fase, foram realizados inicialmente levantamentos bibliográficos a respeito da evolução do potencial eólico no Brasil e no Rio Grande do Norte e do processo de licenciamento ambiental para tal atividade econômica nesse estado.

Na outra fase, chamada de exploração do material, obteve-se os dados necessários para a posterior análise e discussão dos resultados. A primeira coleta deu-se a partir da aplicação de questionário fechado com o gestor da Bioconsultants Consultoria em Recursos Naturais e Meio Ambiente a fim de detalhar os gastos monetários para a obtenção da Licença Prévia, a Licença de Instalação e a Licença de Operação de 4 (quatro) parques eólicos localizados no RN e se o empreendedor teve algum problema com a população que reside próxima às áreas dos parques durante a realização dos estudos ambientais.

A segunda coleta ocorreu com o objetivo de obter o tempo de vigência e o tempo de tramitação das Licenças Prévia, de Instalação e de Operação através de entrevistas semiestruturadas com o subcoordenador de Licenciamento de parques eólicos do Instituto de Desenvolvimento Sustentável e Meio Ambiente do RN - IDEMA.

Ainda na segunda fase da pesquisa, foram coletados dados da evolução histórica e dos potenciais atuais de instalação e operação de parques eólicos no Rio Grande do Norte junto ao Centro de Estratégia em Recursos Naturais e Energia do RN - CERNE, que estava em processo de finalização de uma pesquisa intitulada "A indústria dos ventos e o Rio Grande do Norte - Brasil" e concedeu algumas informações relevantes para o desenvolvimento desse trabalho.

A última etapa da coleta de dados se deu por meio da obtenção da lista de documentos e estudos ambientais necessários para o licenciamento dos empreendimentos eólicos no RN. Também foram coletados os preços requeridos pelo IDEMA para a análise das licenças ambientais de empreendimentos de parques eólicos. Tais dados foram coletados no sítio eletrônico do IDEMA.

Após o levantamento dos dados acerca do tempo de tramitação, dos gastos financeiros e da exigência de estudos ambientais para cada tipo de licença, foi realizada a terceira etapa da pesquisa, tratamento de dados, por meio da análise da complexidade do licenciamento de empreendimentos eólicos com base nos dados coletados na fase anterior.

Devido a não existência de estudos prévios acerca do tema em questão, principalmente no que diz respeito a um critério de análise da complexidade do processo licitatório, optou-se pela análise das licenças a partir dos seguintes critérios: a complexidade dos documentos, a 
quantidade de documentos requeridos em cada tipo de licença, a complexidade dos estudos ambientais requisitados, a quantidade de profissionais necessários para elaborar os documentos de cada licença e os recursos materiais para a elaboração dos documentos.

Tais critérios foram criados com base nos levantamentos bibliográficos e nos dados da pesquisa.

\section{REFERENCIAL TEÓRICO}

\subsection{SUSTENTABILIDADE AMBIENTAL}

As questões relativas à sustentabilidade começaram a ser iniciadas, ainda que de forma acadêmica, a partir de meados do século XIX, com o apogeu da revolução industrial e a exacerbação do impacto ambiental ocasionado pelas atividades antrópicas.

Oficialmente, o conceito de desenvolvimento só foi assumido pelos governos e organismos multilaterais a partir de $1987 \mathrm{com}$ a publicação do Relatório Brundtland, segundo o qual desenvolvimento sustentável é "suprir as necessidades da geração presente sem afetar a habilidade das gerações futuras de suprir as suas" (TRIGUEIRO, 2005; MARCOVITCH, 2006; SANTOS, 2010; BORGES et al., 2006).

De acordo com Savitz (2007), esse conceito se desenvolveu durante a década de 1980 devido a uma maior conscientização por parte dos países que necessitavam encontrar meios de promover o crescimento de suas economias sem destruir o meio ambiente ou sacrificar o bemestar das gerações futuras. Neste sentido, a sustentabilidade pode ser entendida como um conceito sistêmico que está direcionado para uma sinergia entre desenvolvimento econômico e preservação ambiental, pois o conceito envolve a interdependência de três aspectos essenciais na sociedade - econômico, social e ambiental - que devem ser trabalhados reconhecendo suas necessidades mútuas. (SANTOS, 2010; SAVITZ, 2007).

A relevância da sustentabilidade e a forma como os governos desenvolvem políticas públicas voltadas para a área começam a definir o rumo político de algumas nações, sendo o debate sobre desenvolvimento sustentável decisivo para determinar os resultados eleitorais em alguns países da Europa (TRIGUEIRO, 2005), além de ter sido o tema mais importante nas eleições presidenciais na Austrália em 2007, ganhando o candidato considerado mais disposto a enfrentar os problemas ambientais do país (SENGE et al., 2009).

Friedman (2010) ressalta a necessidade de enfrentar os desafios ambientais em um mundo "quente, plano e lotado", não somente pelas mudanças climáticas, mas também pela ascensão da classe média com alto padrão de consumo em países emergentes e o aumento da população mundial que ultrapassará os 9 bilhões de habitantes em 2050 (KRUGLIANSKAS et al., 2009).

A maior conscientização sobre o tema se deve a necessidade de transição de um modelo de desenvolvimento oriundo da Revolução Industrial para um modelo baseado em princípios sustentáveis. Senge et al. (2009) sugerem que essa mudança no modelo de desenvolvimento apresente três ideias norteadoras: a) Nenhum caminho para o futuro ignora as necessidades das gerações futuras; b) As instituições importam (o mundo é moldado não por indivíduos isolados, mas por uma rede de empresas e instituições governamentais e não governamentais); c) Todas as mudanças reais se fundamentam em novas maneiras de pensar e perceber. 
Portanto, é preciso o avanço e formulação de estratégias e políticas de desenvolvimento, consolidando e aliando conceitos e experiências que visam um modelo alternativo de sustentabilidade e de uma sociedade que vise minimizar seus impactos ao meio ambiente.

\subsection{ENERGIA EÓLICA}

Denomina-se energia eólica a energia cinética contida nas massas de ar em movimento (vento). Seu aproveitamento ocorre por meio da conversão da energia cinética de translação em energia cinética de rotação, com o emprego de turbinas eólicas - também denominadas aerogeradores - para a geração de eletricidade, ou cataventos (e moinhos) para trabalhos mecânicos, como bombeamento d'água (ANEEL, 2005).

Assim como a energia hidráulica, a energia eólica é utilizada há milhares de anos com as mesmas finalidades, a saber: bombeamento de água, moagem de grãos e outras aplicações que envolvem energia mecânica. Para a geração de eletricidade, as primeiras tentativas surgiram no final do século XIX, mas somente um século depois, com a crise internacional do petróleo (década de 1970), é que houve interesse e investimento suficiente para viabilizar o desenvolvimento e aplicação de equipamentos em escala comercial (ANEEL, 2005).

Foi a partir de experiências de estímulo ao mercado, realizadas na Califórnia (década de 1980), Dinamarca e Alemanha (década de 1990), que o aproveitamento eólio-elétrico atingiu escala de contribuição mais significativa ao sistema elétrico em termos de geração e economicidade. O desenvolvimento tecnológico passou a ser conduzido pelas nascentes indústrias do setor, em regime de competição, impulsionado por mecanismos institucionais de incentivo - especialmente via remuneração pela energia produzida (CEPEL, 2001).

A capacidade de energia eólica instalada no mundo cresceu $21 \%$ em 2011, passando de 197.000 para $238.000 \mathrm{MW}$ (equivalente a 17 vezes a potência instalada de Itaipu, igual a 14.000 MW). Somente na América Latina, o crescimento em 2011 foi de 60\% (CERNE, 2012).

Esse crescimento de mercado fez com que a Associação Europeia de Energia Eólica estabelecesse novas metas, indicando que, até 2020 , a energia eólica poderá suprir $10 \%$ de toda a energia elétrica requerida no mundo. Atualmente, cerca de 90 países possuem usinas eólicas comerciais, sendo que 22 deles são capazes de gerar pelo menos 1 GW (GWEC, 2005).

Para o sistema elétrico brasileiro, a energia eólica ainda é uma opção complementar à fonte hidrelétrica. Contudo, a participação da energia eólica vem aumentando consideravelmente nos últimos anos, principalmente desde a criação em 2002 do Programa de Incentivo às Fontes Alternativas de Energia Elétrica - PROINFA - sendo o maior programa do mundo de incentivo às fontes alternativas de energia elétrica. Posteriormente, ocorreram sucessivos leilões de compra e venda deste tipo de energia, contribuindo com a participação na matriz elétrica brasileira de um pouco mais de $20 \mathrm{MW}$ para aproximadamente $1.180 \mathrm{MW}$ (ENERGIA, 2010).

A expectativa estimada é que até 2020 a capacidade energética instalada no país aumente em 63.400 MW. O compromisso estabelecido pelo governo é diversificar a matriz energética, organizar leilões que contratem energia pelo menor preço e que garantam a sustentabilidade ambiental (ENERGIA, 2010).

Dados do Atlas do Potencial Eólico Brasileiro (2001) apontam que o potencial eólico do Brasil para aproveitamento energético tem sido objeto de estudos e inventários desde os anos 1970 e o seu histórico revela o lento, mas progressivo descortinamento de um potencial energético natural de relevante magnitude existente no país. Para o Global Wind Energy Council, 
organização internacional que reúne entidades e empresas relacionadas à produção de energia eólica, o Brasil é o país mais promissor do mundo em termos de produção dessa energia.

Estudos sucessivos e medições em locais estratégicos do nordeste brasileiro destacam essa região como o maior potencial do país para a implantação da energia eólica, seguida das regiões sudeste, sul e norte (ALVES, 2010). Mapas eólicos desenvolvidos pelo Centro Brasileiro de Energia Eólica apontam que a área tem uma das melhores jazidas do mundo, contam com boa velocidade de vento, baixa turbulência e uniformidade. O potencial total é estimado em 30 mil MW. Em termos estratégicos, este tipo de matriz é de grande importância, porque os ventos são mais fortes nos períodos de seca (entre junho e dezembro), quando a produção das hidrelétricas tende a cair (ENERGIA, 2010).

Observando a evolução dos Estados brasileiros nos leilões de energia eólica organizados pelo Governo Federal entre 2009 e 2011, percebe-se a posição de destaque do estado do Rio Grande do Norte como o maior produtor de energia eólica em relação à potência instalada até 2016. Em 4 anos, o Rio Grande do Norte terá energia eólica equivalente a países como Portugal ou Dinamarca e o número de aerogeradores aumentará de 300 para mais 3 mil,passando da condição de importador absoluto de energia para a de provedor regional (CERNE, 2012). Isso significa investimento e PIB gerado no Estado e conforto energético para atrair outros setores para o RN.

Dentre alguns benefícios do incentivo de energias alternativas à matriz energética brasileira, a energia eólica contribui de maneira representativa para a redução da emissão de gases intensificadores do efeito estufa através da atividade de usinas térmicas, de poluentes atmosféricos; diminui a necessidade da construção de grandes reservatórios; e reduz o risco gerado pela sazonalidade hidrológica, uma vez que ela operará em conjunto com as usinas hidrelétricas, trazendo em médio prazo uma menor tarifa ao consumidor.

\subsection{LICENCIAMENTO AMBIENTAL}

A Constituição Federal previu, em seu art. 225, que "todos têm direito ao meio ambiente ecologicamente equilibrado, bem de uso comum do povo e essencial à sadia qualidade de vida, impondo-se ao Poder Público e à coletividade o dever de defendê-lo e preservá-lo para as presentes e futuras gerações." Com isso, o meio ambiente tornou-se direito fundamental do cidadão, cabendo tanto ao governo quanto a cada indivíduo o dever de resguardá-lo.

A defesa do meio ambiente apresenta-se também como princípio norteador e inseparável da atividade econômica na Constituição Federal. Desse modo, não são admissíveis atividades da iniciativa privada e pública que violem a proteção do meio ambiente (BRASIL, 2007).

O licenciamento ambiental trata-se de um procedimento administrativo pelo qual o órgão ambiental competente, com objetivo preventivo e desde que preenchidos pelo empreendedor os requisitos normativos exigidos, licencia a construção, a instalação, a ampliação e o funcionamento de estabelecimentos e atividades potencialmente poluidoras ou degradadoras do meio ambiente.

Em síntese, qualquer empreendimento potencialmente poluidor ou degradador do meio ambiente deverá está sujeito ao licenciamento ambiental, em tese, com a obtenção sucessiva de Licença Prévia (LP), Licença de Instalação (LI) e Licença de Operação (LO). Mesmo aquele que não cause impacto ambiental significativo está sujeito a licenciamento, embora dispense a elaboração do Estudo de Impacto Ambiental e Relatório de Impacto Ambiental - EIA/RIMA, 
classificado como o estudo que envolve maior complexidade, substituindo por outro estudo mais simplificado ou específico (BORATTO, 2005).

Ressalta-se que o EIA/RIMA não é o único estudo ambiental considerado no processo de licenciamento. Outros estudos, que abordam os aspectos ambientais relacionados à localização, instalação e operação de uma atividade ou empreendimento, podem se configurar como subsídio à análise de licença requerida, como o Plano de Controle Ambiental - PCA e Relatório de Controle Ambiental - RCA, dentre outros (BRASIL, 2009).

As principais diretrizes para a execução do licenciamento ambiental estão expressas na Lei 6.938/81 e nas Resoluções CONAMA no 001/86 e no 237/97. Além dessas, recentemente foi publicado a Lei Complementar no 140/2011, que discorre sobre a competência estadual e federal para o licenciamento, tendo como fundamento a localização do empreendimento.

A licença ambiental é, portanto, uma autorização emitida pelo órgão público competente. Ela é concedida ao empreendedor para que exerça seu direito à livre iniciativa, desde que atendidas às precauções requeridas, a fim de resguardar o direito coletivo ao meio ambiente ecologicamente equilibrado.

\subsection{LICENÇAS AMBIENTAIS}

As licenças ambientais estão estabelecidas no Decreto 99.274/90, que regulamenta a Lei 6.938/81, e detalhadas na Resolução CONAMA no 237/97 (BRASIL, 2009).

Para cada etapa do processo de licenciamento ambiental é necessária a licença adequada: no planejamento de um empreendimento ou de uma atividade, a licença prévia (LP); na construção da obra, a licença de instalação (LI); e na operação ou funcionamento, a licença de operação (LO).

A Licença Prévia (LP) atestará a viabilidade ambiental do empreendimento, aprovará sua localização e concepção e definirá as medidas mitigadoras e compensatórias dos impactos negativos do projeto. Para as atividades consideradas efetivas ou potencialmente causadoras de significativa degradação ambiental, a concessão da licença prévia dependerá da apresentação dos documentos não técnicos e da aprovação dos documentos técnicos e do estudo ambiental (EIA/RIMA, Relatório Ambiental Simplificado - RAS, Relatório de Controle Ambiental - RCA, outros). Esses documentos deverão ser norteados de acordo com Termo de Referência específico solicitados pelo órgão ambiental competente.

Durante o processo de obtenção da licença prévia são analisados diversos fatores que definirão a viabilidade ou não do empreendimento que se pleiteia. É nessa fase que:

- São levantados os impactos ambientais e sociais prováveis do empreendimento;

- São avaliadas a magnitude e a abrangência de tais impactos;

- São formuladas medidas que, uma vez implementadas, serão capazes de eliminar ou atenuar os impactos;

- São ouvidos os órgãos ambientais das esferas competentes;

- São ouvidos órgãos e entidades setoriais, em cuja área de atuação se situa o empreendimento;

- São discutidos com a comunidade, caso haja audiência pública, os impactos ambientais e respectivas medidas mitigadoras e compensatórias; e

- É tomada a decisão a respeito da viabilidade ambiental do empreendimento, levando-se em conta sua localização e seus prováveis impactos, em confronto com as medidas mitigadoras dos impactos ambientais e sociais. 
A Licença de Instalação (LI) autoriza a instalação do empreendimento ou atividade de acordo com as especificações constantes dos planos, programas e projetos aprovados pelo órgão ambiental, incluindo as medidas de controle ambiental e demais condicionantes, da qual constituem motivo determinante (BRASIL, 2009).

Dependendo do tipo, do porte, da localização e do potencial de impacto ambiental do empreendimento poderá ser solicitado algum tipo de estudo ambiental (Plano de Controle Ambiental - PCA, Programa de Recuperação de Áreas Degradadas - PRAD, Relatório Detalhado de Programas Ambientais - RDPA, outros) que deverá ser desenvolvido de acordo com Termo de Referência específico, fornecido após a vistoria da área (RIO GRANDE DO NORTE, 2006).

Ao conceder a licença de instalação, o órgão gestor de meio ambiente terá:

- Autorizado o empreendedor a iniciar as obras;

- Concordado com as especificações constantes dos planos, programas e projetos ambientais, seus detalhamentos e respectivos cronogramas de implementação;

- Verificado o atendimento das condicionantes determinadas na licença prévia;

- Estabelecido medidas de controle ambiental, com vistas a garantir que a fase de implantação do empreendimento obedecerá aos padrões de qualidade ambiental estabelecidos em lei ou regulamentos;

- Fixado as condicionantes da licença de instalação (medidas mitigadoras e/ou compensatórias).

A Licença de Operação (LO) autoriza a operação da atividade ou empreendimento. Tem por finalidade aprovar a forma proposta de convívio do empreendimento com o meio ambiente e estabelecer condicionantes para a continuidade da operação.

A LO possui três características básicas:

- É concedida após a verificação pelo órgão ambiental, do efetivo cumprimento das condicionantes estabelecidas nas licenças anteriores (prévia e de instalação);

- Contém as medidas de controle ambiental (padrões ambientais) que servirão de limite para o funcionamento do empreendimento ou atividade; e

- Especifica as condicionantes determinadas para a operação do empreendimento, cujo cumprimento é obrigatório, sob pena de suspensão ou cancelamento da operação.

O licenciamento é um compromisso, assumido pelo empreendedor junto ao órgão ambiental, de atuar conforme o projeto aprovado. A licença não tem caráter definitivo e, portanto, sujeita o empreendedor à renovação, com condicionantes supervenientes (BRASIL, 2007).

\section{ANÁLISE E DISCUSSÃO DOS RESULTADOS}

Os resultados serão demonstrados nas tabelas abaixo e posteriormente comentados a partir das três perspectivas de análise: custo, tempo e complexidade.

Tabela 1: Resposta do questionário com a Bioconsultants

\begin{tabular}{|l|c|c|c|c|}
\hline & Parque 1 & Parque 2 & Parque 3 & Parque 4 \\
\hline Localização do parque & Areia Branca & $\begin{array}{c}\text { São Miguel do } \\
\text { Gostoso }\end{array}$ & Parazinho & João Câmera \\
\hline Tamanho do parque & Médio & Pequeno & Pequeno & Pequeno \\
\hline
\end{tabular}




\begin{tabular}{|c|c|c|c|c|}
\hline \multicolumn{5}{|c|}{ Licença Prévia (LP) } \\
\hline $\begin{array}{l}\text { Pessoas para elaborar a } \\
\text { LP }\end{array}$ & 5 a 6 & 3 a 4 & 3 a 4 & 3 a 4 \\
\hline Custo apenas da LP (R\$) & 579,46 & 130,38 & 130,38 & 130,38 \\
\hline Custos variáveis ( $R \$)$ & $\begin{array}{c}\text { Mais de } 23 \\
\text { mil }\end{array}$ & 11 a $16 \mathrm{mil}$ & 11 a $16 \mathrm{mil}$ & 17 a $22 \mathrm{mil}$ \\
\hline Estudo ambiental (EA) & RCA & RCA & RCA & RCA \\
\hline Custo do EA (R\$) & $\begin{array}{c}100 \text { a } 200 \\
\mathrm{mil}\end{array}$ & 100 a $200 \mathrm{mil}$ & 100 a $200 \mathrm{mil}$ & 100 a $200 \mathrm{mil}$ \\
\hline Complexidade do EA & Média & Média & Média & Média \\
\hline \multicolumn{5}{|c|}{ Licença de Instalação (LI) } \\
\hline $\begin{array}{l}\text { Pessoas para elaborar a } \\
\text { LI }\end{array}$ & 5 a 6 & 3 a 4 & 3 a 4 & 5 a 6 \\
\hline Custo apenas da LI (R\$) & 869,18 & 304,21 & 304,21 & 304,21 \\
\hline Custos variáveis ( $\mathrm{R} \$$ ) & 30 a $35 \mathrm{mil}$ & 20 a $25 \mathrm{mil}$ & $\begin{array}{c}\text { Menos de } 15 \\
\text { mil }\end{array}$ & 20 a $25 \mathrm{mil}$ \\
\hline Estudo ambiental (EA) & $\begin{array}{l}\text { RDPA e } \\
\text { PRAD }\end{array}$ & RDPA e PRAD & RDPA e PRAD & RDPA e PRAD \\
\hline Custo do EA (R\$) & $\begin{array}{c}250 \text { a } 350 \\
\text { mil }\end{array}$ & 150 a $250 \mathrm{mil}$ & 150 a $250 \mathrm{mil}$ & 150 a $250 \mathrm{mil}$ \\
\hline Complexidade do EA & Alta & Alta & Alta & Alta \\
\hline \multicolumn{5}{|c|}{ Licença de Operação (LO) } \\
\hline \begin{tabular}{|l} 
Pessoas para elaborar a \\
LO
\end{tabular} & 5 a 6 & 3 a 4 & 3 a 4 & 3 a 4 \\
\hline Custo apenas da LO (R\$) & 869,18 & 304,21 & 304,21 & 304,21 \\
\hline Custos variáveis (R\$) & $\begin{array}{c}\text { Mais de } 40 \\
\text { mil }\end{array}$ & 30 a 40 mil & 20 a $30 \mathrm{mil}$ & 30 a $40 \mathrm{mil}$ \\
\hline Estudo ambiental (EA) & PCA & PCA & PCA & PCA \\
\hline Custo do EA (R\$) & $\begin{array}{c}250 \text { a } 350 \\
\text { mil }\end{array}$ & 250 a $350 \mathrm{mil}$ & 150 a $250 \mathrm{mil}$ & 250 a $350 \mathrm{mil}$ \\
\hline Complexidade do EA & Média & Média & Média & Média \\
\hline
\end{tabular}

Fonte: elaborado pelos autores.

Tabela 2: Itens necessários para elaboração de cada documento e documentos requisitados nos três tipos de licença

\begin{tabular}{|l|l|l|}
\hline Documentos & Itens utilizados para avaliar a complexidade dos & Documentos \\
\hline
\end{tabular}




\begin{tabular}{|c|c|c|c|c|c|c|c|}
\hline \multirow{2}{*}{$\begin{array}{l}\text { necessários no } \\
\text { processo de } \\
\text { licenciamento }\end{array}$} & \multicolumn{4}{|c|}{ documentos } & \multicolumn{3}{|c|}{$\begin{array}{l}\text { requisitados } \\
\text { na } L P, L I, L O\end{array}$} \\
\hline & $\begin{array}{l}\text { Órgãos } \\
\text { externos }\end{array}$ & $\begin{array}{c}\text { Conhecimentos } \\
\text { específicos }\end{array}$ & $\begin{array}{l}\text { Profissional } \\
\text { da área }\end{array}$ & $\begin{array}{c}\text { Meio } \\
\text { ambiente }\end{array}$ & LP & LI & LO \\
\hline $\begin{array}{l}\text { Documento de } \\
\text { pessoa jurídica ou } \\
\text { física }\end{array}$ & & & & & $x$ & & \\
\hline $\begin{array}{l}\text { Documento de } \\
\text { legalidade do uso da } \\
\text { área }\end{array}$ & $x$ & & & & $x$ & & \\
\hline $\begin{array}{l}\text { Certidão da } \\
\text { prefeitura } \\
\text { municipal/ alvará de } \\
\text { localização do } \\
\text { empreendimento }\end{array}$ & $x$ & & & & $x$ & & \\
\hline $\begin{array}{l}\text { Memorial descritivo } \\
\text { da área do projeto }\end{array}$ & & $x$ & $x$ & $x$ & $x$ & & \\
\hline $\begin{array}{l}\text { Descrição sucinta do } \\
\text { empreendimento }\end{array}$ & & $x$ & $x$ & $x$ & $x$ & & \\
\hline $\begin{array}{l}\text { Projeto do } \\
\text { empreendimento }\end{array}$ & & $x$ & $x$ & $x$ & & $x$ & \\
\hline $\begin{array}{l}\text { Memorial descritivos } \\
\text { de funcionamento, } \\
\text { plantas, cortes e } \\
\text { detalhes }\end{array}$ & & $x$ & $x$ & & & $x$ & \\
\hline $\begin{array}{l}\text { Plantas de } \\
\text { localização }\end{array}$ & & $x$ & $x$ & $x$ & $x$ & & \\
\hline $\begin{array}{l}\text { Planta de rede } \\
\text { coletora de águas } \\
\text { pluviais }\end{array}$ & & $x$ & $x$ & $x$ & & $x$ & \\
\hline $\begin{array}{l}\text { Planta } \\
\text { planialtimétrica }\end{array}$ & & $x$ & $x$ & $x$ & $x$ & & \\
\hline $\begin{array}{l}\text { Cronograma de } \\
\text { elaboração de } \\
\text { planos, programas e } \\
\text { projetos }\end{array}$ & & $x$ & & & $x$ & & \\
\hline Estudos ambientais & $x$ & $x$ & $x$ & $x$ & $x$ & $x$ & $x$ \\
\hline $\begin{array}{l}\text { Cronograma físico } \\
\text { de implementação } \\
\text { do empreendimento }\end{array}$ & & $x$ & & & & $x$ & \\
\hline $\begin{array}{l}\text { Anotações de } \\
\text { responsabilidade } \\
\text { técnica }\end{array}$ & & $x$ & $x$ & & $x$ & $x$ & $x$ \\
\hline
\end{tabular}




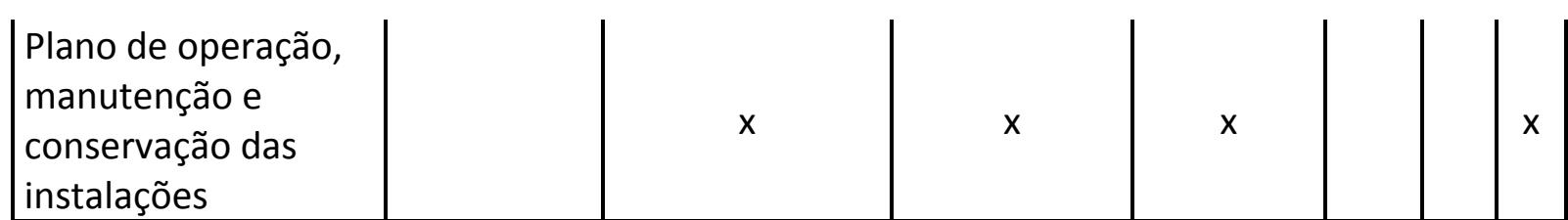

Fonte: elaborado pelos autores.

\section{- Tempo}

Através de entrevistas semiestruturadas com o subcoordenador de Licenciamento de parques eólicos do IDEMA foi obtido que o tempo de tramitação de resposta do referido órgão, em média, desde que seja cumprido todo o termo de referência e condicionantes, à Licença Prévia são 30 (trinta) dias, e à Licença de Instalação e Licença Operacional em torno de 12 (doze) dias. A lei estabelece no máximo 60 (sessenta) dias de resposta.

Sobre o tempo de vigência, após a aprovação da Licença Prévia são 2 (dois) anos em vigor e para Licença de Instalação e Operacional são 4 (quatro) anos.

\section{- Custos}

Segundo a resolução $n^{\circ}$ 02/2011 do Conselho Estadual do Meio Ambiente (CONEMA), para fins de enquadramento do empreendimento e/ou atividade com o objetivo de determinar o preço da análise dos processos de licenciamento ambiental, devem ser considerados o porte do empreendimento e o potencial poluidor/degradador do mesmo.

Com exceção das atividades petrolíferas, o porte dos empreendimentos está divido em 5 (cinco) categorias: Micro, Pequeno, Médio, Grande e Excepcional. Para empreendimentos eólicos o parâmetro adotado para a classificação do porte é a potência gerada em MW pelo empreendimento. Parques eólicos, portanto, são classificados em Micro (até $5 \mathrm{MW}$ ), Pequeno (de 6 a $15 \mathrm{MW}$ ), Médio (de 16 a $45 \mathrm{MW}$ ), Grande (de 46 a $135 \mathrm{MW}$ ) e Excepcional (maior que $135 \mathrm{MW})$.

De acordo com a mesma resolução, empreendimentos eólicos são caracterizados como empreendimentos de pequeno potencial poluidor.

A partir dessa classificação e de acordo com o disposto no anexo à portaria 002/2012 do IDEMA que trata da atualização de preços para a análise das licenças ambientais, obteve-se os valores referentes a cada licença que se encontram na tabela 1.

A partir dos dados na tabela1, temos que o parque 1 apresenta os maiores custos tanto no preço da licença, nos custos variáveis e os custos referentes ao estudo ambiental. Isso ocorre devido ao fato do parque 1 ter o maior porte, e, portanto, apresenta maiores custos nas licenças ambientais, e, consequentemente, por ser uma área maior, o custo do estudo ambiental (na Licença de Instalação) foi maior. Devido ao fato de estar localizado em Areia Branca, o município mais distante da capital (Natal - onde a sede da empresa se localiza) em comparação com os outros listados, o parque 1 apresenta um custo variável maior, visto que foram necessários mais recursos para o processo de construção e funcionamento do parque, como o caso da gasolina e diárias.

Já o parque 3, apresenta os menores custos variáveis, como também os menores preços dos estudos ambientais, principalmente, no caso da Licença de Operação. Tal situação ocorre porque o parque apresenta porte pequeno e de acordo com o questionário respondido pela Bioconsultants, houve nesse projeto uma menor solicitação de demandas em relação aos estudos ambientais por parte da empresa contratante. 


\section{- Complexidade}

O primeiro critério analisado foi a complexidade dos documentos, com a adoção de quatro itens avaliadores, sendo eles: órgãos externos, conhecimentos específicos, profissional da área e meio ambiente. $O$ primeiro aborda a necessidade ou não de a empresa consultar órgãos externos em busca de dados, documentos específicos e relatórios. O segundo classifica quanto à necessidade de ter um profissional com conhecimentos específicos para elaborar o documento. O terceiro item retrata a obrigação ou não de apresentar no documento a assinatura de um profissional técnico em uma área específica. E o quarto, retrata se os documentos envolvem estudos diretos do meio ambiente onde será implantado o parque eólico.

Os documentos foram obtidos da listagem do sítio eletrônico fornecido pelo IDEMA. Foram classificados como documentos de alta complexidade aqueles que apresentaram os quatros itens; de média complexidade aqueles que apresentaram três itens e de baixa complexidade aqueles documentos que tinham dois ou menos itens.

Foi eleito, por conseguinte, como de alta complexidade: estudos ambientais; como de média complexidade: memorial descritivo da área do projeto, descrição sucinta do empreendimento, projeto do empreendimento, planta de localização, planta de redes coletora de águas pluviais, e plano de operação, manutenção e conservação das instalações; e como de baixa complexidade: documentos de pessoa física ou jurídica, documento de legalidade do uso da área, certidão da prefeitura municipal / alvará de localização do empreendimento, memorial descritivo de funcionamento, plantas, cortes e detalhes, planta planialtimétrica, cronograma de elaboração de planos, programas e projetos, cronograma físico de implementação do empreendimento, e anotação de responsabilidade técnica.

O segundo critério de análise foi a quantidade de documentos requeridos pelo órgão ambiental em cada licença. De acordo com os termos de referência, para a obtenção da Licença Prévia são requisitados 10 (dez) documentos, sendo que um deles foi classificado como de alta complexidade (estudos ambientais) e quatro deles foram classificados como de média complexidade. Para a Licença de Instalação são pedidos 6 (seis) documentos, dentre eles um documento é de alta complexidade e 2 (dois) de média complexidade. Por fim, para a obtenção da Licença de Operação, o órgão ambiental requer a entrega de apenas 3 (três) documentos, sendo um deles algum estudo ambiental (alta complexidade) e o Plano de Operação, Manutenção e Conservação das Instalações (média complexidade).

A quantidade de profissionais necessários para a elaboração dos documentos requisitados pelo IDEMA foi outro ponto de análise. Pode-se perceber pela tabela 1 que a quantidade necessária depende do porte e das características do empreendimento e não do tipo de licença, pois nos parques 2, 3 e 4 (pequeno porte) foram utilizados de 3 a 4 profissionais para a elaboração dos documentos para a obtenção da Licença Prévia, Licença de Instalação e de Operação. Com uma ressalva na Licença de Instalação, um dos parques de pequeno porte (o quarto) destoou quanto à quantidade de pessoas, pois apresentava características diferenciadas, visto que o parque era isolado e houve uma demanda maior por parte do contratante.

Quanto aos recursos e materiais necessários, o tipo de licença e o tipo de estudo ambiental determinam o que será necessário. No caso da Licença Prévia, em todos os parques foram requisitados papel, gasolina, computador, mão de obra externa qualificada, máquina fotográfica, ArcGIS/Autocad, EPI e GPS. Na Licença de Instalação e de Operação foram necessários os mesmos recursos da Licença Prévia acrescentando a rede de neblina, pinção de captura de serpentes, decibelímetro e caixa para transporte de animais. 
Em relação aos estudos ambientais, segundo resposta do gestor da consultoria ambiental, os estudos requeridos na Licença de Instalação (PRAD e RDPA) foram os mais complexos. Tal fato é contraditório se comparado ao licenciamento ambiental geral, pois na Licença Prévia são pedidos os estudos considerados mais complexos, como o EIA/RIMA por exemplo. Nesse caso, uma justificativa para esse resultado é a necessidade de estabelecer procedimentos simplificados para o licenciamento ambiental de empreendimentos de pequeno potencial poluidor, como a indicação do RAS na Licença Prévia por meio da resolução CONAMA n² 279/01 ou a utilização do RCA - utilizada pelo IDEMA nos parques em questão - para empreendimentos eólicos.

Os estudos requeridos na Licença de Instalação são os documentos que apresentam detalhadamente todas as medidas de controle e os programas ambientais propostos no Relatório de Controle Ambiental da etapa anterior do licenciamento, tendo, portanto, maior nível de detalhamento na sua elaboração.

Adicionalmente aos dados da tabela 1 , foi observado, através do questionário respondido pela consultoria ambiental, que houve a solicitação de providências pelo órgão ambiental no processo de licenciamento ambiental de todos os parques eólicos da presente pesquisa. Além disso, constatou-se que existem dificuldades junto à população local impactada pela construção dos parques eólicos, principalmente no que diz respeito à mudança de hábito da população por causa da construção, o desconhecimento da população em relação à atividade e a poeira causada pela implementação da obra.

Tais dificuldades podem causar custos extras ao empreendedor, pois pode haver a necessidade de elaboração de estudos adicionais para constatar a viabilidade do empreendimento, bem como a necessidade de realizar audiências públicas para o esclarecimento dos benefícios e impactos advindos do empreendimento eólico.

\section{CONSIDERAÇÕES FINAIS}

A partir dos dados coletados e dos consequentes resultados, conclui-se que a complexidade das licenças ambientais será principalmente determinada a partir do estudo ambiental requisitado. Como há uma incerteza em qual estudo ambiental será requisitado, principalmente na Licença Prévia, existe uma dificuldade de se estabelecer qual licença ambiental é a mais complexa para a sua obtenção. Nesse trabalho, dentre os parques pesquisados, teve-se que a licença de instalação possuiu os estudos ambientais mais complexos de acordo com a visão do gestor da consultoria ambiental, o que de certa forma é contraditório se comparado com a maioria dos licenciamentos ambientais onde a Licença Prévia é a mais complexa, visto que os estudos ambientais possivelmente requisitados nessa etapa - EIA/ RIMA, RAS ou RCA - são os mais detalhados e decisivos para a continuidade do processo licitatório.

Foi possível observar que a ausência de padronização quanto aos estudos ambientais que serão requisitados pelo órgão ambiental ao empreendedor, tanto em nível estadual como federal, é uma realidade que afeta diretamente ao empreendedor e ao meio ambiente. A dificuldade surge no momento em que o empreendedor não sabe previamente o que lhe será requisitado, não podendo, por conseguinte, realizar um fiel planejamento de investimento devido à ausência de informações.

Outra conseqüência é o fato de um órgão ambiental em um determinado estado não pedir um estudo compatível com a complexidade socioambiental do local e facilmente um empreendedor instalar o parque eólico nesse local afetando diretamente o meio ambiente, como 
também, o órgão requisitar um estudo de alta complexidade em uma região que não necessita de tantas exigências, inviabilizando o projeto do empreendedor.

Referente aos custos de cada tipo de licença ambiental, conclui-se que a margem de custos pode variar significativamente, pois os custos estão intrinsecamente ligados ao porte do empreendimento, tipo de estudo ambiental requisitado, distância do empreendimento da sede e dificuldades com a população, podendo chegar a valores consideravelmente maiores do que os apresentados nos parques estudados.

Vale salientar que o processo licitatório é de vital importância para a preservação integral do meio ambiente, sendo a sua não realização por parte do empreendedor passível de sanções legais, como previstas na lei 9.605/98 que trata sobre crimes ambientais.

A partir das pesquisas realizadas, foi possível observar o crescimento do uso do potencial eólico no Brasil, acompanhando, portanto, a tendência mundial do uso dessa fonte energética. Tal situação foi viabilizada pelo crescimento dessa indústria no Brasil, que hoje apresenta um maior desenvolvimento econômico e tecnológico, cujo preço encontra-se perto da energia proveniente das hidrelétricas, detentora do maior potencial energético brasileiro. Por fim, sugere-se para futuros estudos complementares o aprimoramento da atual pesquisa, reportando uma maior quantidade de parques eólicos, com diversos portes em diferentes regiões a fim de fornecer um maior detalhamento dos dados com o intuito de subsidiar o desenvolvimento da energia eólica de forma sustentável do ponto de vista econômico e socioambiental.

\section{REFERÊNCIAS BIBLIOGRÁFICAS}

1. AGÊNCIA NACIONAL DE ENERGIA ELÉTRICA (ANEEL). Atlas de energia elétrica do Brasil. 2. ed. Brasília: ANEEL,2005. Disponível em: <http://www.aneel.gov.br/aplicacoes/Atlas/download.htm>. Acesso em: 29 jul. 2012.

2. ALVES, José JaksonAmancio. Análise Regional da energia eólica no Brasil. Revista Brasileira de Gestão e Desenvolvimento Regional, v.6, n.1, p. 165 - 188, jan./abr. 2010.

3. ANDRADE, Rui Otávio Bernardes de; TANCHIZAWA, Takeshy; CARVALHO, Ana Barreiros de. Gestão Ambiental: enfoque estratégico aplicado ao desenvolvimento sustentável. São Paulo: Makron Books, 2002.

4. BARDIN, I. Análise de conteúdo. Lisboa: Edições Setenta, 1994.

5. BORATTO, Maurício Viana. Legislação sobre Licenciamento Ambiental: Histórico, controvérsias e perspectivas. Brasília: Biblioteca Digital da Câmara dos Deputados, 2005. Disponível em: <http://bd.camara.leg.br/bd/bitstream/handle/bdcamara/1234/legislacao_licenciamento_bo ratto.pdf?sequence=1>. Acesso em: 16 ago. 2012.

6. BORGES, César; CORTEZ, Fátima; PONTES, Raquel. Desenvolvimento: formas e processos. Fortaleza: Fundação Konrad Adenauer, 2006.

7. BRASIL. Ministério do Meio Ambiente. Caderno de Licenciamento Ambiental. Brasília, DF, 2009. $90 \quad$ p. 90 Disponível em: <http://www.mma.gov.br/estruturas/dai_pnc/_arquivos/pnc_caderno_licenciamento_ambie ntal_01_76.pdf>. Acesso em: 13 ago. 2012. 
8. Tribunal de Contas da União. Cartilha de licenciamento ambiental. 2. ed. Brasília: TCU, 2007. Disponível em: <http://portal2.tcu.gov.br/portal/pls/portal/docs/2059156.PDF>. Acesso em: 14 ago. 2012.

9. CENTRO DE ESTRATÉGIAS EM RECURSOS NATURAIS E ENERGIA (CERNE). A indústria dos ventos e o Rio Grande do Norte - Brasil. Natal: CERNE, 2012. No prelo.

10. CENTRO DE PESQUISA DE ENERGIA ELÉTRICA (CEPEL).Atlas do Potencial Eólico Brasileiro. Brasília: CEPEL, 2001. Disponível em: $<$ http://www.cresesb.cepel.br/publicacoes/download/atlas_eolico/Atlas\%20do\%20Potencial \%20Eolico\%20Brasileiro.pdf>. Acesso em: 19 ago. 2012.

11. ENERGIA eólica. Portal Brasil, [S. I.], 2010. Disponível em: <http://www.brasil.gov.br/sobre/economia/energia/matriz-energetica/energia-eolica>. Acesso em: 25 jul. 2012.

12. FRIEDMAN, Thomas L. Quente, plano e lotado: os desafios e oportunidades de um novo mundo. Rio de Janeiro: Objetiva, 2010.

13. GLOBAL WIND ENERGY COUNCIL (GWEC). WIND FORCE 12. [S. I.]: Greenpeace, 2005.Disponível em: <http://www.ewea.org/fileadmin/ewea_documents/documents/publications/WF12/wf122005.pdf>. Acesso em: 13 ago. 2012.

14. KRUGLIANSKAS, Isak; ALIGLERI, Lilian; ALIGLERI, Luiz A. Gestão socioambiental: responsabilidade e sustentabilidade do negócio. São Paulo: Atlas, 2009.

15. MARCOVITCH, Jacques. Para mudar o futuro: mudanças climáticas, políticas públicas e estratégias empresariais. São Paulo: Saraiva, 2006.

16. NEVES, José Luis. Pesquisa qualitativa - características, usos e possibilidades.Caderno de pesquisa em administração, São Paulo, v.1, n.3, p.103 - 113, 1996.

17. RIO GRANDE DO NORTE (Estado). Instituto de Desenvolvimento Econômico e Meio Ambiente do Rio Grande do Norte. Instruções Técnicas para Apresentação de Projetos de Geração de Energia Elétrica - Licença de Instalação (LI). Rio Grande do Norte, 2006. 3 p.Disponível em: <http://www.idema.rn.gov.br/arquivos/Licenciamento/Documentos\%20T\%C3\%A9cnicos\%20 por\%20Atividade\%20ou\%20Tipo\%20de\%20Servi\%C3\%A7o/Gera\%C3\%A7\%C3\%A3o\%20de\%2 OEnergia\%20EI\%C3\%A9trica/IT\%20-

\%20Gera\%C3\%A7\%C3\%A30\%20de\%20Energia\%20EI\%C3\%A9trica\%20_LI_.pdf>. Acesso em: 13 ago. 2012.

18. SANTOS, Hellen Dantas dos. TI verde: interesses organizacionais e tecnologia da informação alinhados pela sustentabilidade. 2010. 98f. Monografia (Tecnólogo em Informática para Gestão de Negócios) - Faculdade de Tecnologia da Zona Leste, São Paulo, 2010.

19. SAVITZ, Andrew W. A empresa sustentável: o verdadeiro sucesso é o lucro com responsabilidade social e ambiental. 2. ed. Rio de Janeiro: Elsevier, 2007.

20. SENGE, Peter. et al. A revolução decisiva: como os indivíduos e as organizações trabalham em parceria para criar um mundo sustentável. Rio de Janeiro: Elsevier, 2009. 
21. SILVA, C.R.; GOBBI, B.C.; SIMÃO, A. A. O uso da análise de conteúdo como uma ferramenta para a pesquisa qualitativa: descrição e aplicação do método.Organizações rurais agroindustriais, Lavras, v.7, n.1, p. 70-81, 2005.

22. STROBEL, J. S.; CORAL, E.; SELIG, P. M. Indicadores de sustentabilidade corporativa: uma análise comparativa. In: ENCONTRO ANUAL DA ANPAD, 28.,2004, Curitiba. Anais eletrônicos... Curitiba: ENANPAD, 2004. 1 CD-ROM.

23. TRIGUEIRO, André. Mundo sustentável: abrindo espaço na mídia para o planeta em transformação. São Paulo: Globo, 2005. 